\title{
Essential medicines for children
}

\author{
Kalle Hoppu, ${ }^{1}$ Shalini Sri Ranganathan ${ }^{2}$
}

\begin{abstract}
${ }^{1}$ Hospital for Children and Adolescents and Department of Clinical Pharmacology, University of Helsinki and Poison Information Centre, Helsinki University Central Hospital, Helsinki, Finland ${ }^{2}$ Department of Pharmacology, Faculty of Medicine, University of Colombo, Colombo, Sri Lanka
\end{abstract}

\section{Correspondence to} Kalle Hoppu, Poison Information Centre, Helsinki University Central Hospital, P.O. Box 790, Helsinki 00029, Finland; kaarlo.hoppu@hus.fi

Received 2 June 2014 Accepted 28 October 2014

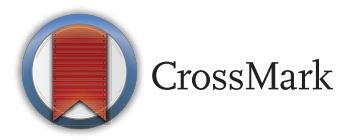

To cite: Hoppu K,

Sri Ranganathan S. Arch Dis Child 2015;100(Suppl 1): s38-s42.

\section{ABSTRACT}

Millions of children die every year before they reach the age of 5 years, of conditions largely treatable with existing medicines. The WHO Model List of Essential Medicines was launched in 1977 to make the most necessary drugs available to populations whose basic health needs could not be met by the existing supply system. During the first 30 years of the Model List of Essential Medicines, children's needs were not systematically considered. After adoption of the 'Better medicines for children' resolution by the World Health Assembly, things changed. The first WHO Model List of Essential Medicines for Children was drawn up by a Paediatric Expert Subcommittee and adopted in October 2007. The most recent, 4th Model List of Essential Medicines for Children was adopted in 2013. Data from country surveys show that access to essential medicines for children is still generally poor; much more work is needed.

Millions of children die every year before they reach the age of 5 years, of conditions treatable with existing medicines. Of newborn deaths $22 \%$ are due to infections such as septicaemia, pneumonia, diarrhoea and malaria. Oral antibiotics administered in community settings can reduce all-cause neonatal mortality by $25 \%$ and pneumonia-specific mortality by $42 \% .{ }^{1}$ Childhood pneumonia and diarrhoea are the most important causes of childhood mortality and account for about $30 \%$ of all child deaths worldwide. ${ }^{2}$ Zinc administration for diarrhoea management is able to reduce all-cause mortality by $46 \%$, and pneumonia-specific mortality by $28 \%{ }^{3}$ The treatments (antibiotics for pneumonia and zinc) are safe and effective, off-patent, inexpensive to manufacture and require no cold chain. Still, scarcely half of children with severe acute pneumonia receive antibiotics, and of children with acute diarrhoea less than $1 \%$ receive zinc. ${ }^{4}$ Lack of medicines is not the single most important health problem of children, but access to appropriate medicines that would make a potential difference in survival is essential for achievement of the Millennium Development Goals (MDGs), especially MDG 4: Reduce child mortality and MDG 6: Combat HIV/ AIDS, malaria and other major diseases.

\section{THE ESSENTIAL MEDICINES CONCEPT}

Essential medicines are those that satisfy the priority healthcare needs of the population. They are selected on the basis of disease prevalence, evidence on efficacy, safety and comparative costeffectiveness. Essential medicines are intended to be available within the context of functioning health systems at all times in adequate amounts, in the appropriate dosage forms, with assured quality, and at a price the individual and the community can afford. ${ }^{5}$ The purpose of the original WHO proposal for the programme of essential medicines was developed in 1975 based on the experience of some countries, like Sri Lanka (then Ceylon), where programmes of basic or essential medicines had been implemented. The objective was to make the most necessary medicines available to populations whose basic health needs could not be met by the existing supply system. ${ }^{67}$

An international Expert Committee was appointed by WHO to recommend how a national essential medicines programme could be implemented. The Expert Committee issued its report in $1977 .{ }^{8}$ The report included the selection criteria for an essential medicine (box 1) and also the first WHO Model List of Essential Medicines (EML) of 208 medicines. Since then the List is updated every 2 years. Its content and the process by which it is updated are intended to be a model for developing countries.

WHO overhauled the process of updating the list in 2002. An important element of the overhaul was the affordability of the medicines. For example, before 2002 effective but expensive medicines were not listed because of their price. Under the new definition 12 antiretroviral (ARV) medicines for HIV/AIDS were listed, despite their high cost at that time. Their listing implied that these medicines should become affordable to all patients who need them; and since then prices have indeed come down dramatically. ${ }^{6}$

The essential medicines concept of purchasing a limited list of essential medicines for a health service and making them available has been widely accepted. Many United Nations agencies, including Unicef and United Nations Refugee Agency, major non-governmental organisations and international non-profit supply agencies limit the medicines they purchase for donations to those on the EML. ${ }^{6}$ The downside is that a medicine not on the Model List will not be donated by such organisations.

\section{THE WHO MODEL LIST OF ESSENTIAL MEDICINES}

The Model List is drawn up by the WHO Expert Committee on the Selection and Use of Essential Medicines usually convened every 2 years. The Committee comprises 8-12 members drawn from the WHO Expert Advisory Panels based on equitable geographical representation, gender balance and professional competencies in order to provide a representation of different approaches and practical experience from all regions of the world. Members of Expert Advisory Panels are proposed by WHO and, when approved by their respective government, appointed for one or more periods of up to 4 years. Meetings of the Expert Committee are closed. Observers may be invited in accordance with WHO Regulations to attend all or parts of the meetings of the Expert Committee. Patient 
Box 1 The criteria for determining if a medicine is essential ${ }^{7}$

- Having adequate evidence of efficacy and safety from clinical studies in a variety of medical settings

- Availability in a form that is made properly with adequate bioavailability and stability under anticipated storage conditions

- The use of the medicine for its indicated purpose has been well established

advocacy groups and representatives of the healthcare industry are invited to comment on the applications and draft recommendations (see below), but are not invited to attend decisionmaking parts of meetings of the Expert Committee.

Relevant departments in WHO or external persons or organisations submit their applications for inclusions, changes or deletions to the Model List electronically using the Expert Committee website to the secretary of the Expert Committee. The process of applications for EML is public and open to any individual willing to submit comments or an application. ${ }^{9} 10$ The choice of essential medicines depends on several factors, including the disease burden and sound and adequate data on the efficacy, safety and comparative cost-effectiveness of available treatments. Stability in various conditions, the need for special diagnostic or treatment facilities and pharmacokinetic properties are also considered if appropriate. When adequate scientific evidence is not available on current treatment of a priority disease, the Expert Committee may either defer the issue until more evidence becomes available, or choose to make recommendations based on expert opinion and experience. ${ }^{7} 11$

\section{NATIONAL ESSENTIAL MEDICINES LISTS}

The WHO EML is a model and is expected to be adapted to the local environment and needs at national or regional levels. National lists of essential medicines provide a public health basis for focus and expenditure in the pharmaceutical sector. They are used to guide the procurement and supply of medicines in the public sector, reimbursement schemes, medicine donations and local medicine production. A successful national adaptation is demonstrated by clear relationships between the national EML, standard treatment guidelines and procurement practices within the country. ${ }^{12}$

Of the 151 countries surveyed in 2007 by WHO 131 had an essential medicines list. ${ }^{13}$ Most developing countries have national lists and some have provincial or state lists as well. ${ }^{6}$ Sri Lanka as an example had a medicines list for the state and private health sector in 1958-1959 (then Ceylon), before the launch of the WHO Model List. However, revisions of the list did not take place regularly until recently (first: 1985, second: 1999, third: 2006, fourth: 2009). Now the fifth revision is about to be published.

The WHO EML has undoubtedly been a success and its 30th anniversary was celebrated in 2007. However, something was missing for the first 30 years (figure 1).

\section{CHILDREN'S MEDICINES ON THE WHO ESSENTIAL MEDICINES LIST}

The first Expert Committee responsible for developing the first EML had eight members, and four temporary advisers, none of them a paediatrician. However, there were two representatives of the Unicef Supply Division. The report mentioned children only once, in the description of the Model drug information sheet (Dosage regimen: Average and range for adults and children). ${ }^{8}$ Although the EML included some paediatric medicines, children's medicines were not systematically considered during the first 30 years of the EML, and the Expert Committee included a paediatrician only three times, in 2003, in 2005 and two in $2007 .^{14-16}$

In 2006 WHO together with Unicef organised an expert consultation to consider ways of tackling the problem of lack of essential medicines for children. Work was already being done by the Finnish government to put paediatric medicines up for discussion at the WHO governing bodies. ${ }^{17}$ In May 2007 the World Health Assembly (WHA) adopted Resolution 'Better medicines for children' (WHA60.20) requesting the WHO Director-General to ensure that all relevant WHO programmes, including but not limited to that on essential medicines, contribute to making safe and effective medicines as widely available for children as for adults. ${ }^{18}$ The same year the first Model List of Essential Medicines for Children (EMLc) was adopted by the 16th Expert Committee on the day of the 30th anniversary of the EML (25 October 2007). ${ }^{19}$

Since then the EMLc has been revised three times and the current version is the fourth..$^{20-22}$ A Paediatric Subcommittee of the Expert Committee developed the first two EMLcs. The third was developed by an Expert Committee with adult and paediatric expertise balanced. Of the applications for inclusion or exclusion of a medicine to/from the EML/EMLc and reviews submitted to the most recent 19th WHO Expert Committee, 41/87 (47\%) concerned children, while 46/87 (53\%) concerned adults. Only $3(19 \%)$ of the 16 members and technical advisors of the Committee had significant paediatric expertise, and none was a clinical paediatrician. ${ }^{22}$

\section{PAEDIATRIC ESSENTIAL MEDICINES AT COUNTRY LEVEL}

With children's needs having been inadequately considered in the WHO EML for 30 years, what essential medicines for children were available in resource-limited settings? WHO performed a study in 2007, before the first EMLc came out, in 14 countries in central Africa to document the inclusion of key children's medicines in national EMLs and standard treatment guidelines, and to assess the availability of key children's medicines in public and private healthcare facilities. ${ }^{23}$ The proportion of survey medicines in the national EMLs ranged from $50 \%$ to $90 \%$, and less than $50 \%$ of 20 medicines needed to treat priority conditions were available in healthcare facilities (table 1). ${ }^{23}$

With the EMLc in place since 2007, has the situation changed? Data from country surveys show that access to essential medicines for children is generally poor. ${ }^{24} 25$

In most developing countries there are no separate EMLs for children: The main list is made 'child-friendly' by adding paediatric formulations and strengths for medicines common to adults and children, and including medicines exclusively for children (eg, specific medicines for neonatal care). Since the local health system dictates medicines supply to different levels of hospitals, a national committee also specifies in which levels of hospitals one particular essential medicine is expected to be available all the times.

Available evidence indicates that despite the national list of essential medicines becoming more 'child friendly' with each revision, children access to these essential medicines has not improved in par. For example in Sri Lanka, a national survey in 
Figure 1 One of the posters commemorating 30 years of WHO Model List for Essential Medicines at the same time highlighting the lack of attention to children's medicines. The first WHO Children's Model List for Essential Medicines was approved at the anniversary meeting (October 2007). Source: http://www.who.int/ entity/medicines/events/ WhereEssentMeds.jpg.

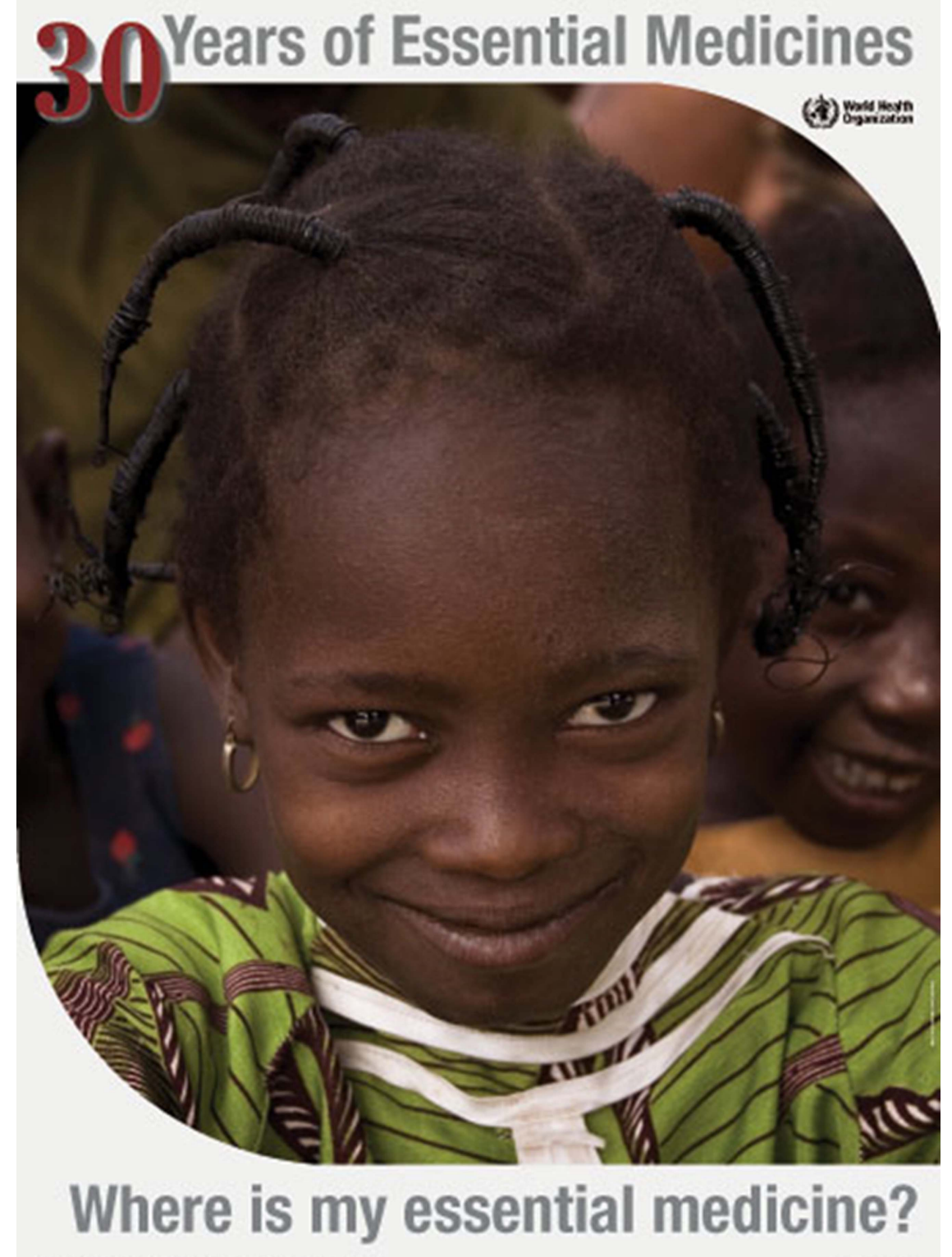

¿Donde está mi medicamento esencial?
Table 1 Availability of 20 key essential medicines for children in 14 countries in central Africa ${ }^{23}$

\begin{tabular}{lc}
\hline Survey medicines available in & $\begin{array}{l}\text { Proportion of medicines } \\
\text { available (\%; range) }\end{array}$ \\
\hline National essential medicines lists (EMLs) & $50-90$ \\
Standard treatment guidelines & $15-100$ \\
Central medical stores (CMS) & $15-75$ \\
NGO stores & $10-65$ \\
Teaching hospitals & $15-70$ \\
District hospitals & $10-80$ \\
Primary healthcare & $18-48$ \\
Retail pharmacies & $38-62$ \\
\hline
\end{tabular}

NGO, non-governmental organisation. of State Pharmaceutical Corporation (ROS) pharmacies. ${ }^{26}$ Teaching/general hospitals had better availability (mean per cent availability 62\%) than district hospitals (54\%), peripheral units (49\%) and central dispensaries (45\%). For example amoxicillin suspension was available in $45 \%$ of the public hospitals compared with $100 \%$ of private and ROS pharmacies. None of the public hospital outpatient department pharmacies, $45 \%$ of private pharmacies and $62.5 \%$ of ROS pharmacies had carbamazepine syrup.

WHO, Unicef and the United Nations Population Fund have identified a list of the top 30 medicines from the EML for maternal and child health, to support countries making choices about medicines for treating women and children. This list of 'priority medicines' was published in April 2011. ${ }^{27} 28$ A study investigated the inclusion of these priority medicines in the national essential medicines lists of 89 countries. ${ }^{13}$ There was considerable global variation in the listing of these priority medicines. The most frequently listed medicine was paracetamol, on 84 lists (94\%). Sodium chloride, gentamicin and oral rehydration solution were on 83 lists (93\%). The least frequently listed medicine was the children's antimalarial rectal artesunate, on 7 
lists (8\%); artesunate injection was on 14 lists $(16 \%)$. Paediatric artemisinin combination therapy, as dispersible tablets or flexible oral solid dosage form, appeared on 32 lists (36\%). Procaine benzyl penicillin, for treatment of paediatric pneumonia and neonatal sepsis, was on 45 lists $(50 \%)$. Zinc, for treatment of diarrhoea in children, was included in only 13 lists $(15 \%) .{ }^{13}$

\section{CHILDREN'S ACCESS TO ESSENTIAL MEDICINES AT GRASS-ROOTS LEVEL}

Access is defined as having medicines continuously available and affordable at public or private medicine outlets that are within $1 \mathrm{~h}$ walk from the homes of the population. ${ }^{29}$ Reachability (availability or physical access), affordability (economic access) and acceptability (sociocultural access) have been identified as essential prerequisites of universal access. ${ }^{30}$ There is often a big gap between the real status of children's access to essential medicines and these technical definitions.

In countries where medicines are given free in public hospitals, and the cost is borne by the public funding, like for example in Sri Lanka, the children may be denied access to these free essential medicines in the public sector because of low availability. Parents are then compelled to pay out-of-pocket to purchase them from the private sector where the availability seems to be better. Additional, important, but mostly undocumented obstacles to children's access to essential medicines at the grass-roots level are listed in box 2 .

\section{MDGS AND ESSENTIAL MEDICINES FOR CHILDREN}

With the low availability of medicines for children, particularly in Africa, it is hardly surprising that child mortality in well-treatable conditions is still a problem. The medicines needed to make a difference in MDGs exist, but not always the age-appropriate formulation, and sometimes data, for example, on the optimal dose is also lacking. Many key medicines, such as zinc for diarrhoea in children, are consistently missing in national essential medicines lists. ${ }^{13}$ While some of the WHO programmes considered the characteristic problems of paediatric medicines, a systematic approach to paediatric medicines by the WHO was missing, as the example of the EML shows, until the WHA resolution 'Better medicines for children' was adopted in 2007.

That change is possible by proper attention to paediatric medicines is illustrated by the improved access of children to HIV/AIDS medicines in resource-limited settings. Increased international support and funding resulted in research evidence that use of generic adult fixed drug combinations could provide

Box 2 Important, but mostly undocumented obstacles to children's access to essential medicines at the grass-roots level

- Non-supply/inadequate supply of liquid formulation of essential medicines

- Shortage of paediatric strength tablets

- Lack of/poor storage and transport facilities

- Irrational prescription in public hospitals leading to non-availability of essential medicines when indicated

- Shortage of even adult strength tablets

- Polypharmacy and irrational prescribing in the private sector inflating the cost of a prescription impinging on affordability

- Poorly marketed essential medicine concept an interim solution for scaling up of ARV treatment in children. ${ }^{31}{ }^{32}$ As a result the proportion of children in need of ARVs, in low-income and middle-income countries receiving them, rose from $7 \%$ in 2005 to $29 \%$ at the end of 2009 (2009 adult coverage was 36\%). ${ }^{33}$ For the MDGs, much more needs to be done to improve access to appropriate paediatric medicines, but developments with ARVs indicate that change is possible. However, even modest improvements take decades not years to achieve, and the EMLc is only 7 years old.

\section{THE OUTLOOK}

From the USA Paediatric legislations 'proof of concept' exists that change is possible ${ }^{34}$ if the problems of children's medicines are acknowledged by the society and comprehensive measures are taken. The US and European Union (EU) Paediatric legislations will improve scientific evidence, and availability of age-appropriate formulations. ${ }^{34}$ However, neither legislation in USA or the EU will directly improve access to Essential Medicines.

Competing interests Dr Hoppu has been a member of the WHO Expert Panel on Selection and Use of Essential Medicines since 2007. He has served on the Expert Committee 2007, 2009, and 2001, on the two Paediatric Subcommittees of the Expert Committee in 2007 and 2008, and attended the 2013 Expert Committee as an observer. Dr Hoppu has been a temporary adviser to several WHO programmes. Dr Sri Ranganathan has served on the Expert Committee in 2013 and on WHO's Paediatric Subcommittee of the Expert Committee of the Selection and Use of Essential Medicines in 2007. She has also served as temporary adviser to two (Essential Medicine and Pharmacovigilance) WHO-South East Asian Region programs (WHO-SEARO)

Provenance and peer review Commissioned; internally peer reviewed.

\section{REFERENCES}

1 Zaidi AK, Ganatra HA, Syed S, et al. Effect of case management on neonatal mortality due to sepsis and pneumonia. BMC Public Health 2011;11(Suppl 3):S13.

2 Walker CL, Rudan I, Liu L, et al. Global burden of childhood pneumonia and diarrhoea. Lancet 2013;381:1405-16.

3 Bhutta ZA, Das JK, Walker N, et al. Interventions to address deaths from childhood pneumonia and diarrhoea equitably: what works and at what cost? Lancet 2013:381:1417-29.

4 Gill CJ, Young M, Schroder K, et al. Bottlenecks, barriers, and solutions: results from multicountry consultations focused on reduction of childhood pneumonia and diarrhoea deaths. Lancet 2013;381:1487-98.

5 Essential medicines. http://www.who.int/medicines/services/essmedicines def/en/

6 Hoppu K, Hogerzeil HV. Global aspects of drug development. In: Seyberth H, Rane A, Schwab M, eds. Springer, Berlin Heidelberg. Pediatric Clinical Pharmacology 2011:353-72.

7 Reidenberg MM. World Health Organization program for the selection and use of essential medicines. Clin Pharmacol Ther 2007;81:603-6.

8 World Health Organization. The selection of essential drugs: report of a WHO expert committee. World Health Organ Tech Rep Ser 1977;(615):1-36.

9 Kishore SP, Herbstman BJ. Adding a medicine to the WHO model list of essential medicines. Clin Pharmacol Ther 2009;85:237-9.

10 Reidenberg MM. Essential medicines for the whole world. Clin Pharmacol Ther 2007:82:500-3

11 Essential medicines selection. WHO Expert Committees. http://www.who.int/ selection medicines/committees/en/

12 Robertson J, Hill SR. The essential medicines list for a global patient population. Clin Pharmacol Ther 2007;82:498-500.

13 Hill S, Yang A, Bero L. Priority medicines for maternal and child health: a global survey of national essential medicines lists. PLOS ONE 2012;7:e38055.

14 World Health Organization. The selection and use of essential medicines. Report of the WHO expert committee, 2005 (including the 14th model list of essential medicines). World Health Organ Tech Rep Ser 2006;933:1-119.

15 World Health Organization. The selection and use of essential medicines. Report of the WHO Expert Committee, 2007 (including the 15th Model List of Essential Medicines). World Health Organ Tech Rep Ser 2007;946:1-162.

16 World Health Organization. The selection and use of essential medicines. Report of the WHO Expert Committee, 2003 (including the 13th Model List of Essential Medicines). World Health Organ Tech Rep Ser 2004;920:1-127.

17 Hoppu K. Reflection: medicines for children-science alone is not enough. Eur J Clin Pharmacol 2013;69(Suppl 1):59-63. 
18 World Health Assembly. Resolution WHA60.20 Better medicines for children. 2007. http:/l www.who.int/entity/childmedicines/publications/WHA6020.pdf (accessed 9.1.2008).

19 World Health Organization. The selection and use of essential medicines. Report of the WHO Expert Committee, October 2007 (including the Model List of Essential Medicines for Children). Technical Report Series. Geneva: WHO, 2008.

20 World Health Organization. The selection and use of essential medicines. Report of the WHO Expert Committee, 2009 (including the 16th WHO Model List of Essential Medicines and the 2nd WHO Model List of Essential Medicines for Children). Geneva: WHO, 2009.

21 World Health Organization. The selection and use of essential medicines. Report of the WHO Expert Committee, 2011 (including the 17th WHO Model List of Essential Medicines and the 3rd WHO Model List of Essential Medicines for Children). Geneva: WHO, 2012.

22 World Health Organization. The selection and use of essential medicines. Report of the WHO Expert Committee, 2013 (including the 18th WHO Model List of Essential Medicines and the 4th WHO Model List of Essential Medicines for Children). Geneva: WHO, 2014.

23 Robertson J, Forte G, Trapsida JM, et al. What essential medicines for children are on the shelf? Bull World Health Organ 2009;87:231-7.

24 Chen W, Tang S, Sun J, et al. Availability and use of essential medicines in China: manufacturing, supply, and prescribing in Shandong and Gansu provinces. BMC Health Serv Res 2010;10:211.

25 Gitanjali B, Manikandan S. Availability of five essential medicines for children in public health facilities in India: a snapshot survey. J Pharmacol Pharmacother 2011;2:95-9.
26 Balasubramaniam R, Beneragama BV, Sri Ranganathan S. A national survey of availability of key essential medicines for children in Sri Lanka. Ceylon Med J 2011:56:101-7.

27 Essential medicines for children. Priority life-saving medicines for women and children. http://www.who.int/childmedicines/prioritymedicines/en/

28 Hill SR. Putting the priorities first: medicines for maternal and child health. Bull World Health Organ 2012;90:236-38.

29 United Nations Development Group. Indicators for monitoring the millennium development goals. New York: United Nations, 2003.

30 WHO/UNAIDS/UNICEF. Monitoring and reporting on the health sector's response towards universal access to HIVIAIDS treatment, prevention, care and support 2007-2010. World Health Organization.

31 Natu SA, Daga SR. Antiretroviral therapy in children: Indian experience. Indian Pediatr 2007:44:339-43.

32 O'Brien DP, Sauvageot D, Zachariah R, et al. In resource-limited settings good early outcomes can be achieved in children using adult fixed-dose combination antiretroviral therapy. AIDS 2006;20:1955-60.

33 WHO/UNAIDS/UNICEF. Towards universal access: Scaling up priority HIVIAIDS interventions in the health sector. 2010. http://www.who.int/hiv/pub/ 2010progressreport/report/en/index.html\%22\%5Ct\%22_blank

34 Hoppu K, Anabwani G, Garcia-Bournissen F, et al. The status of paediatric medicines initiatives around the world-what has happened and what has not? Eur I Clin Pharmacol 2012;68:1-10. 